\title{
Gibberellin $\mathrm{A}_{59}$ : A New Gibberellin from Canavalia gladiata
}

\author{
Takao YoKoTA and Nobutaka TAKAHASHI \\ Department of Agricultural Chemistry, \\ The University of Tokyo, \\ Bunkyo-ku, Tokyo 113, Japan \\ Received January 12, 1981
}

\begin{abstract}
Gibberellin $\mathrm{A}_{59}$ has been isolated from immature seeds of Canavalia gladiata (sword bean) and its structure was determined to be $\Delta^{2}$-gibberellin $\mathrm{A}_{21}(\mathbf{1})$.
\end{abstract}

Canavalia gladiata is a unique legume in that its immature seed produces $\mathrm{C} 18$-oxidized gibberellins, $\mathrm{GA}_{21}$ and $\mathrm{GA}_{22} \cdot{ }^{1,2)}$ Such gibberellins have not been found from any other sources including higher plants or fungi. This prompted us to reinvestigate its endogenous gibberellins.

The acidic fraction obtained from immature seeds was purified by silica gel partition chromatography. ${ }^{3)}$ Biological activity of each fraction thus obtained was examined by dwarf rice test (Fig. 1). ${ }^{4}$ ) The eluate with $45 \%$ ethyl acetate which showed the strongest growthpromoting activity was purified by TLC to afford $\mathrm{GA}_{22}$ and a new gibberellin which was named $\mathrm{GA}_{59}$ based on the MacMillan and Takahashi's proposal. ${ }^{57}$ In the dwarf rice microdrop test ${ }^{6)} \mathrm{GA}_{59}$ did not show activity up to $1 \mu \mathrm{g}$ per plant (Table I). Therefore, the activity

Table I. Potency of $G_{59}$ IN the

TAN-GINBOZU MICRODROP TEST

Data expressed as length of 2 nd leaf sheath in $\mathrm{mm} \pm$ standard error $(n=5)$. Controls, $23.7 \pm 0.7$.

\begin{tabular}{lcccc} 
& \multicolumn{5}{c}{ Dosage, $\mu \mathrm{g} /$ plant } \\
\cline { 2 - 5 } $\mathrm{GA}$ & 0.001 & 0.01 & 0.1 & 1 \\
\hline $\mathrm{GA}_{3}$ & $32.6 \pm 1.9$ & $47.8 \pm 2.0$ & $76.4 \pm 2.2$ & $70.8 \pm 2.0$ \\
$\mathrm{GA}_{59}$ & & $22.0 \pm 0.7$ & $22.0 \pm 0.4$ & $22.0 \pm 2.0$ \\
$\mathrm{GA}_{21}$ & & $23.0 \pm 0.3$ & $27.0 \pm 0.7$ & $28.6 \pm 1.0$
\end{tabular}

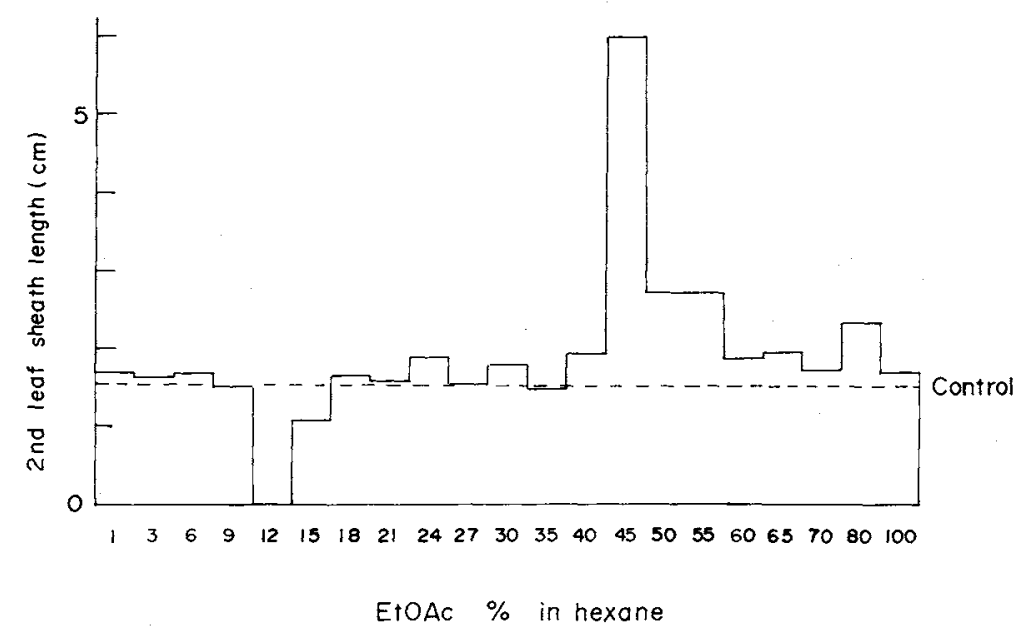

FIG. 1. Distribution of Biological Activity after Silica Gel Partition Chromatography.

For details of procedure, see text. $8 \mathrm{~g}$ fr. wt. equivalents were used for Tan-ginbozu water-culture test. 


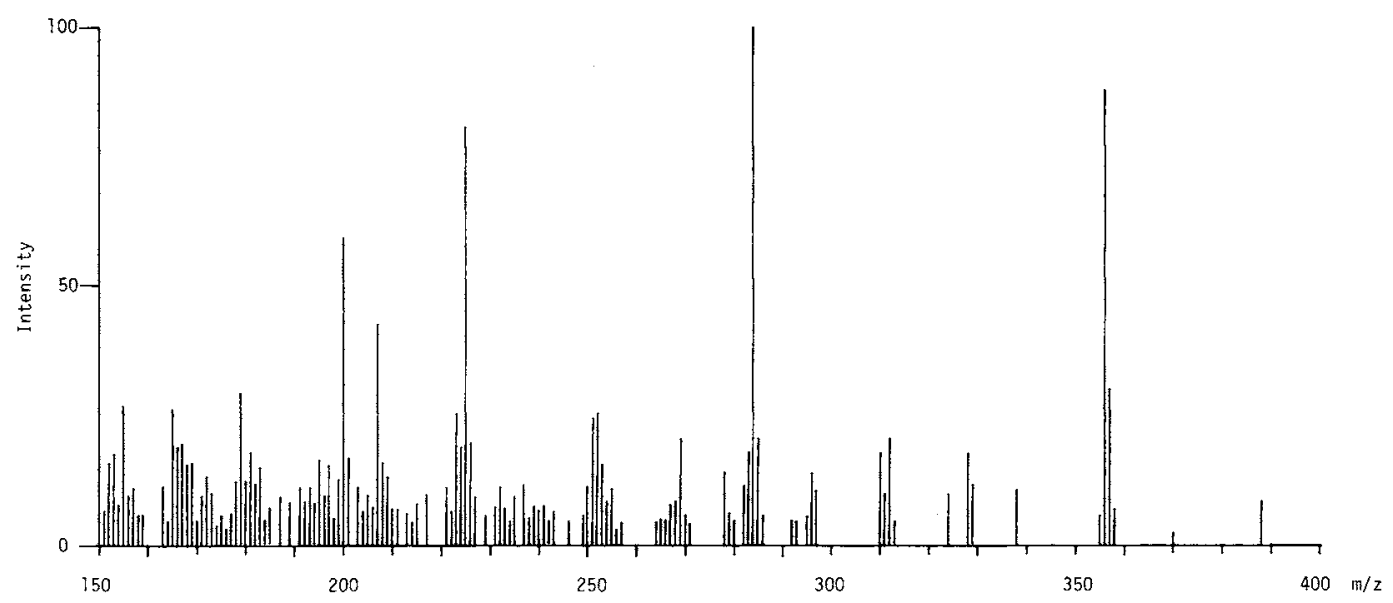

FIG. 2. Mass Spectrum of $\mathrm{GA}_{59}$ Methyl Ester $(40 \mathrm{eV})$.

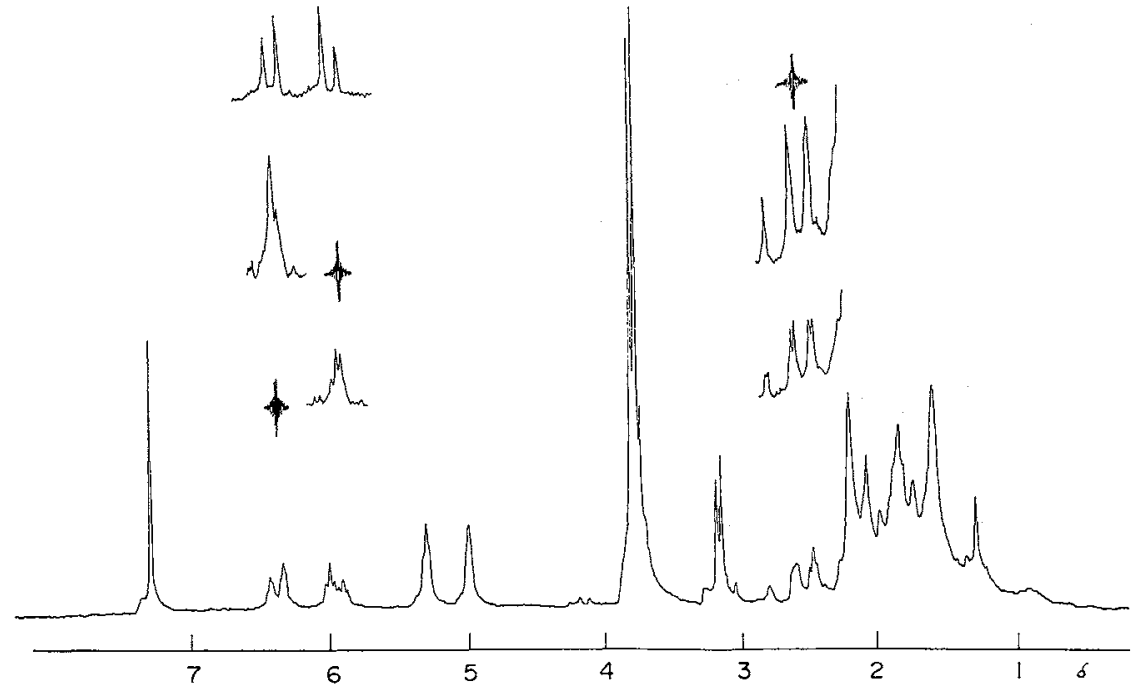

FIG. 3. ${ }^{1} \mathrm{H}$ NMR Spectrum of $\mathrm{GA}_{59}$ Methyl Ester $(100 \mathrm{MHz})$ in $\mathrm{CDCl}_{3}$.

of the $45 \%$ ethyl acetate fraction will be due to $\mathrm{GA}_{22}$,

$\mathrm{GA}_{59}$ was treated with diazomethane to afford a dimethyl ester. The mass spectrum of the ester, obtained by GC-MS, is shown in Fig. 2. In the high resolution MS the molecular ion peak is observed at $m / z 388.1529$ $\left(\mathrm{C}_{21} \mathrm{H}_{24} \mathrm{O}_{7}\right)$. The base peak at $m / z 284.1400$ $\left(\mathrm{C}_{18} \mathrm{H}_{20} \mathrm{O}_{3}\right)$ is due to elimination of carbon dioxide and methyl formate from the molecular ion. This ion is degraded into an ion at $m / z 225.1232\left(\mathrm{C}_{16} \mathrm{H}_{17} \mathrm{O}\right)$ with loss of a methoxycarbonyl, which is confirmed by the presence of a metastable peak at 178.2. Further loss of water gives rise to a hydrocarbon peak at $m / z 207.1086\left(\mathrm{C}_{16} \mathrm{H}_{15}\right)$, as was indicated by a metastable peak at 190.5 . These facts indicate that $\mathrm{GA}_{59}$ carries two carboxyls, one lactone, one hydroxyl and two double bonds. Fragmentation pattern down to $m / z 250$ resembles that of $\mathrm{GA}_{21}$ dimethyl ester although peaks due to $\mathrm{GA}_{59}$ methyl ester are found at two mass units lower than that of $\mathrm{GA}_{21}$ dimethyl ester, suggesting that $\mathrm{GA}_{59}$ is a dehydro derivative of $\mathrm{GA}_{21}$.

In the ${ }^{1} \mathrm{H}$ NMR spectrum ${ }^{7)}$ of the methyl ester in deuterochloroform (Fig. 3) the protons at $\mathrm{C} 5$ and $\mathrm{C} 6$, which are characteristic of 
gibberellins, appear as a pair of doublets at $\delta 3.06$ and $3.19(J=10 \mathrm{~Hz})$. Two methoxycarbonyl groups are observed at $\delta 3.74$ and 3.77 but no $\mathrm{C}$-methyl group is detected, indicating that $\mathrm{GA}_{59}$ is a gibberellin with the oxidized C18. The exocyclic methylene protons are observed as a pair of broad singlets at $\delta 4.95$ and 5.26. A large downfield-shift of the latter signal in deuteropyridine $(\delta 5.63)$ strongly indicates the presence of a hydroxyl at C13. The endocyclic olefin protons are observed at $\delta 6.34(1 \mathrm{H} \text {, broad double triplet, } J=10 \mathrm{~Hz})^{*}$ and $5.91(1 \mathrm{H}$, double triplet, $J=3,10 \mathrm{~Hz})$. It was found in the double resonance experiment (Fig. 3) that these protons are coupled with methylene protons at $\delta 2.66(1 \mathrm{H}$, broad doublet, $J$ (geminal $)=20 \mathrm{~Hz})$ and $2.33(1 \mathrm{H}$, broad doublet, $J$ (geminal) $=20 \mathrm{~Hz}$ ). Therefore the double bond must be located only in the $A$ ring. One of the olefinic protons absorbs at the unusually low field $(\delta 6.34)$ compared with those of $\mathrm{GA}_{5}$ methyl ester (5.65), ${ }^{8)} \mathrm{GA}_{31}$ (5.67 in deuteroacetone), ${ }^{8,9)}$ and $\mathrm{GA}_{22}$ methyl ester $(5.85)^{2,8)}$ This suggests that this proton should be in the vicinity (i.e. $\mathrm{C} 3$ position) of the $\mathrm{C} 4$ methoxycarbonyl group which is to exhibit a deshielding effect. ${ }^{10)}$ Thus it is indicated that the double bond is situated between $\mathrm{C} 2$ and C3. All evidences above-cited, together with biosynthetic view-points, allow us to assign the structure 1 to $\mathrm{GA}_{59}$.

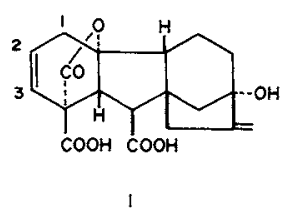

The other fractions obtained after the partition chromatography were analyzed as follows. The $50 \%$ ethyl acetate fraction was purified by TLC, methylated and analysed by GC-MS, resulting in the identification of $\mathrm{GA}_{21}$ (major) and $\mathrm{GA}_{59}$. The $24 \%$ ethyl acetate fraction was methylated and purified by TLC

* This proton was observed as a sharp double triplet $(J=2,10 \mathrm{~Hz})$ when measured in deuteropyridine (see EXPERIMENTAL). to afford a compound, which was identified as $\mathrm{GA}_{59}$ dimethyl ester based on GC-MS. Since the $R f$ value of the original acid was similar to that of $\mathrm{GA}_{5}$, but much larger than that of $\mathrm{GA}_{59}$, it is tentatively assigned as a monomethyl ester of $\mathrm{GA}_{59}$. This fact may suggest occurrence of a glucosyl ester of $\mathrm{GA}_{59}$ in the seed since the $\mathrm{GA}_{59}$ monomethyl ester is likely to be formed by methanolysis of the conjugate during the methanol extraction. The inhibitory activity found in the $12 \%$ and $15 \%$ ethyl acetate fractions were ascribed to abscisic acid based on TLC analysis.

\section{EXPERIMENTAL}

NMR spectra were taken with a JEOL FX-100 spectrometer. Unless otherwise stated the data shown in the text was obtained in $\mathrm{CDCl}_{3}$ using tetramethylsilane as an internal standard. GC-MS was carried out with a Hitachi RMU-6L spectrometer ( $40 \mathrm{eV}$ ) equipped with a Hitachi 063 gas chromatograph. A glass column packed with $2 \%$ OV-1 $(1 \mathrm{~m} \times 3 \mathrm{~mm})$ was used. High resolution mass spectra were taken with JEOL JMS-D300 spectrometer $(90 \mathrm{eV})$.

TLC was performed using Merck silica gel TLC plates with solvent $\mathrm{A}\left(\mathrm{EtOAc}-\mathrm{CHCl}_{3}-\mathrm{AcOH}=15: 5: 1\right)$ and solvent $\mathrm{B}\left(\mathrm{CHCl}_{3}-\mathrm{MeOH}-\mathrm{AcOH}-\mathrm{H}_{2} \mathrm{O}=80: 20: 5: 2\right)$. Elution was effected with $\mathrm{MeOH}$. After the $\mathrm{MeOH}$ was removed, the residue was mixed with stad. $\mathrm{NaCl}$ soln, acidified $(\mathrm{pH} 2)$ with dil. $\mathrm{HCl}$ and extracted 5 times with EtOAc to give gibberellin fractions. Gibberellins and ABA were detected as fluorescent spots under an UV light after heating the TLC plate treated with $70 \% \mathrm{H}_{2} \mathrm{SO}_{4}$.

Bioassay was carried out using the Tan-ginbozu water culture method ${ }^{4)}$ or microdrop method. ${ }^{63}$

Methylation was performed with ethereal diazomethane.

Purification procedure.

Extraction. Immature seeds $(400 \mathrm{~g})$ were extracted with $\mathrm{MeOH}$. The extract, after evaporating the $\mathrm{MeOH}$, was partitioned 3 times against EtOAc at $\mathrm{pH}$ 3. The EtOAc phase was fractionated into an acidic and neutral fraction.

Partition chromatography. ${ }^{3)}$ The acidic fraction was purified on a column $(2.7 \times 22 \mathrm{~cm})$ made of $50 \mathrm{~g}$ silica gel impregnated with $31.3 \mathrm{ml}$ of $0.5 \mathrm{M}$ aq. formic acid which was beforehand saturated with $1 \%$ EtOAc in hexane. Hexane-EtOAc mixtures saturated with $0.5 \mathrm{M}$ formic acid were used for elution with increasing EtOAc contents (Fig. 1). Eluates were collected in $400 \mathrm{ml}$ fractions.

$T L C$. The eluate with $12 \%$ and $15 \%$ EtOAc showed a yellow-green fluorescent spot at $R f 0.42$ on TLC (solvent 
A), which indicated the presence of cis,trans-ABA. Thus the inhibitory activity of these fractions may be due to cis,trans-ABA.

The eluate with $24 \%$ EtOAc showed a GA-like spot at $R f 0.37$ (cf. $R f$ of $\mathrm{GA}_{5}=0.40, R f$ of $\mathrm{GA}_{21}=0.10$ ) on TLC (solvent A). This fraction was esterified and purified by TLC (ether; $R f c a .0 .5$ ) to affford $\mathrm{GA}_{59}$ dimethyl ester.

The eluate with $45 \%$ EtOAc was subjected to TLC (solvent B). The zone at Rf $0.54 \sim 0.61$ afforded $\mathrm{GA}_{22}$, which was identified by GC-MS of its methyl ester, whilst the zone at $R f 0.22 \sim 0.28$ yielded $\mathrm{GA}_{59}$ (less than $1 \mathrm{mg}$ ), $\mathrm{mp} 248^{\circ} \mathrm{C}$ (decomposition). $\mathrm{GA}_{59}$ was converted into a dimethyl ester. NMR (in $\mathrm{C}_{5} \mathrm{D}_{5} \mathrm{~N}$ ): $3.34(1 \mathrm{H}, \mathrm{d}, J=10)$, $3.50(1 \mathrm{H}, \mathrm{d}, J=10), 3.65(3 \mathrm{H}, \mathrm{s}), 3.68(3 \mathrm{H}, \mathrm{s}), 5.06(1 \mathrm{H}$, broad s), $5.63(1 \mathrm{H}$, broad s), $5.85(1 \mathrm{H}, \mathrm{dt}, J=3,10), 6.50$ $(1 \mathrm{H}, \mathrm{dt}, J=2,10)$. MS (high resolution): 388.1529 (388.1523 calcd for $\mathrm{C}_{21} \mathrm{H}_{24} \mathrm{O}_{7}$ ), 284. 1400 (284.1411 calcd for $\mathrm{C}_{18} \mathrm{H}_{20} \mathrm{O}_{3}$ ), 225.1232 (225.1279 calcd for $\mathrm{C}_{16} \mathrm{H}_{17} \mathrm{O}$ ), $207.1086\left(207.1173\right.$ calcd for $\mathrm{C}_{16} \mathrm{H}_{15}$ ), 200.0844 (200.0838 calcd for $\mathrm{C}_{13} \mathrm{H}_{12} \mathrm{O}_{2}$ ). Trimethylsilyl derivative of the ester showed the following MS in GC-MS: $460\left(\mathrm{M}^{+}, 38 \%\right), 445$ (4), $428(7), 401(13), 356(8), 343(12), 238(6), 235(5), 208$ (15), $207(22), 193(15), 180(7), 167(11), 141$ (7), 139 (4), $75(18), 73(100)$.

The eluate with $50 \%$ EtOAc was purified by TLC (solvent $\mathrm{A}$ ). The zone at $R f 0.1$ afforded a mixture of $\mathrm{GA}_{21}$ (major) and $\mathrm{GA}_{59}$. The zone with a higher $R f$ value yielded needles which crystallised from $\mathrm{H}_{2} \mathrm{O}$ and melted (decomposed) at $259^{\circ} \mathrm{C}$. From the mass spectrum $\left(\mathrm{M}^{+}\right.$ $170)$ this compound was identified as gallic acid.

Chromatographic behaviors of $G A_{21}, G A_{22}$ and $G A_{59}$. $R f \mathrm{~s}$ in TLC (solvent $\mathrm{B}): 0.50\left(\mathrm{GA}_{22}\right), 0.28\left(\mathrm{GA}_{21}\right), 0.22$ $\left(\mathrm{GA}_{59}\right)$. Rts in GC $\left(2 \% \mathrm{QF}-1,230,37 \mathrm{ml} / \mathrm{min} \mathrm{N}_{2}\right): 14.1$ $\left(\mathrm{GA}_{22} \mathrm{Me}\right), 18.8\left(\mathrm{GA}_{21} \mathrm{Me}\right), 19.6 \mathrm{~min}\left(\mathrm{GA}_{59} \mathrm{Me}\right)$.
Acknowledgment. We are grateful to Dr. H. Hirota, Department of Chemistry, for measuring high-resolution mass spectra.

\section{REFERENCES}

1) N. Murofushi, N. Takahashi, T. Yokota, J. Kato, Y. Shiotani and S. Tamura, Agric. Biol. Chem., 33, 592 (1969).

2) N. Murofushi, N. Takahashi, T. Yokota and S. Tamura, Agric. Biol. Chem., 33, 598 (1969).

3) L. E. Powell and K. J. Tautvydas, Nature, 213, 292 (1967); R. C. Durley, A. Crozier, R. P. Pharis and G. E. McLaughlin, Phytochemistry, 11, 3029 (1972); T. Yokota, Shokubutsu-no-Kagakuchosetsu, 9, 51 (1974).

4) T. Yokota, N. Murofushi and N. Takahashi, Phytochemistry, 10, 2943 (1971), N. Murofushi and T. Yokota, Kagaku-to-Seibutsu, 17, 51 (1979).

5) J. MacMillan and N. Takahashi, Nature, 217, 170 (1968).

6) Y. Murakami, Bot. Mag. (Tokyo), 81, 33 (1968).

7) J. R. Hanson, J. Chem. Soc., 1965, 5036.

8) N. Takahashi, Plant Growth Substances 1973 (Abstracts of Papers, 8th Int. Conf. Plant Growth Subst.), Hirokawa Publishing Co., Tokyo, 1974, pp. $228 \sim 240$.

9) N. Murofushi, T. Yokota, A. Watanabe and N. Takahashi, Agric. Biol. Chem., 37, 1101 (1973).

10) L. M. Jackman and S. Sternhell, "Applications of Nuclear Magnetic Resonance Spectroscopy in Organic Chemistry," 2nd Ed., Pergamon Press, 1969, pp. $88 \sim 92$. 